\title{
Clinicopathological Factors Associated with Remnant or Regrowth of Benign Breast Tumor after Previous Vacuum-Assisted Core Biopsy
}

\author{
Won Gong Choo, Chang Wan Jeon, Dong Won Ryu \\ Department of Surgery, Kosin University Gospel Hospital, Busan, Korea
}

Purpose: We sometimes encounter remnant or regrowth of benign breast tumors diagnosed as Breast Imaging-Reporting and Data System (BI-RADS) C4 in follow-up breast ultrasound after previous vacuum-assisted core biopsy (VACB). We aimed to evaluate the factors that influence remnant or regrowth tumors at post-VACB site or adjacent tissue. Methods: From January 2010 to December 2015, we analyzed 647 cases on follow-up. Patients were divided into two groups; group A was defined as patients without recurrent masses on breast ultrasonography during the follow-up period, and group B was defined as those with recurrent masses diagnosed as more than BI-RADS C4 on ultrasonography. Results: Fibrocystic changes, proliferative disease without atypia, intraductal papilloma, apocrine cell change, atypical ductal hyperplasia, sclerosing adenosis, and radial scars were observed in $89.5 \%(n=579), 15.9 \%(n=103), 15.3 \%(n=99), 5.3 \%(n=34), 5.7 \%$ $(n=37), 7.6 \%(n=49)$, and $6.3 \%(n=41)$ of patients, respectively. During the follow-up period, 85 patients were diagnosed as group B. Group $\mathrm{B}$ was significantly associated with proliferative diseases without atypia, sclerosing adenosis, and microcalcifications compared to group $\mathrm{A}$ $(p=0.008, p=0.007$, and $p=0.001$, respectively). After adjustment for confounding variables, group B was more significantly associated with proliferative breast diseases than group A (hazard ratio [HR], 0.558; $95 \%$ confidence interval [Cl], 0.343-0.907; $p=0.018$ ). Furthermore, group B was more significantly associated with intraductal papilloma (HR, $0.571 ; 95 \% \mathrm{Cl}, 0.342-0.953 ; p=0.032$ ). Conclusion: Previously diagnosed proliferative diseases without atypia or microcalcification at first VACB were significantly associated with recurrent breast tumor. Intraductal papilloma was also significantly associated with tumor regrowth.

Key Words: Intraductal papilloma, Recurrence

\section{INTRODUCTION}

Vacuum-assisted core biopsy (VACB) is a minimally invasive method used in the diagnosis and treatment of focal breast lesions [1]. Various advantages of VACB have made it a commonly used procedure to diagnose breast lesions. VACB allows removal of multiple tissue samples at a single attempt in a relatively short time, and the patient is able to patients are discharged from the hospital soon [2]. VACB is primarily a diagnostic method for focal breast lesions. Focal lesions in the breast requiring histopathological examination are the primary indications for this procedure [3]. In some cases, VACB can be used therapeutically. It is not used to treat malignant lesions because the samples obtained in this procedure are fragmented, which make it impossible to precisely establish the margin of the removed tissue [4]. However,

Correspondence: Dong Won Ryu

Department of Surgery, Kosin University Gospel Hospital, 262 Gamcheon-ro, Seo-gu, Busan 49267, Korea

Tel: +82-51-990-6462, Fax: +82-51-246-6093, E-mail: lovebreast@naver.com

This article was supported by Kosin Medical Colleage Fund.

Received: Nov 4, 2016 Revised: Feb 14, 2017 Accepted: Mar 6, 2017 for treating small benign lesions, VACB is currently used as a minimally invasive alternative to open surgical biopsy [5]. Benign breast disease (BBD) is a heterogeneous condition consisting of many histological entities, including ductal proliferation with or without atypia, fibroadenomas, and intraductal papillomas [6]. Some of these lesions are thought to represent progressive changes in the stepwise sequence of histological changes leading to the development of breast cancer. Specifically, it has been hypothesized that nonatypical proliferative forms of BBD, proliferative diseases with atypia, and in situ cancer represent successive steps preceding the development of invasive breast carcinoma [7]. We have occasionally encountered tumor regrowth in sites where VACB was previously performed or in adjacent tissues. Hence, we aimed to evaluate the factors that influence tumor regrowth at post-biopsy sites or at adjacent tissues.

\section{METHODS}

Patients

The medical records and pathological reports of 647 patients from 
therapeutic Mammotome (Ehicon, Cincinnati, USA) biopsies performed in the Department of Surgery of Kosin University Hospital from January 2010 to December 2015 were reviewed. The patients were divided into two groups; group A was defined as those without recurrent masses on breast ultrasonography during the follow-up periods, and group B was defined as those with recurrent masses diagnosed as more than Breast Imaging-Reporting and Data System (BIRADS) C4 on ultrasonography. We aimed to compare the clinicopathological features, treatment strategies, and clinical outcomes of post-VACB with and without recurrent masses on breast ultrasonography and to determine their prognostic factors. All VACB and surgical excisions were performed by the same experienced surgeons. A pathologist examined the samples in the laboratory of Kosin University Hospital. The patients with histopathological diagnosis of benign lesions were followed up with clinical and ultrasound examinations after 3, 6, and 12 months. All women with atypical ductal hyperplasia (ADH), ductal carcinoma in situ, or invasive cancer were qualified for surgical excision. The median follow-up time was 11 months (range, 4-38 months). The exclusion criteria were as follows: (1) patients who refused to give informed consent for undergoing VACB; (2) those who were allergic to local anesthetics; and (3) those with active skin infections on the breast. The inclusion criterion was cases diagnosed as BIRADS category 5 . This study was approved by the Institutional Review Board of the Kosin University (IRB number: 201509-BR-013).

\section{Procedure}

Breast ultrasonographic examinations were performed using a Siemens ACUSON S2000 US system (Siemens Medical Solutions, Mountain View, USA) with a linear probe (9L4; Siemens Medical Solutions). A single surgeon performed the biopsies under local anesthesia. A small skin incision (4 mm) was made and the probe was positioned into the lesion by ultrasound-guidance. The acquisition of tissue was performed in different ways and from different angles, as needed. The number of samples varied according to the size of the lesion. Finally, hemostasis was achieved by performing manual compression for 10 minutes. The patients were instructed to inform the radiologist or visit the hospital in case they developed any complications after the procedure. Criteria for making a diagnosis of benign lesions included specific findings such as fibroadenoma, papilloma, phyllodes tumors, as well as nonspecific findings such as fibrosis and fibrocystic changes. For patients who met the aforementioned criteria, they were advised to undergo mammographic or ultrasonographic follow-up in 6 months. In situations of discordance between imaging and histologic findings, surgery was proposed.

\section{Statistical analyses}

Groups were compared with chi-square test or Fisher exact test, as appropriate. Statistical tests were performed using SPSS 12.0 statistical software package for Windows (SPSS Inc., Chicago, USA). The chisquare test was used to evaluate correlation between pathologic benign diseases and clinicopathological parameters in all cases. A p-value $<0.05$ was considered as statistically significant. A Cox regression analysis was used to compute the risk of BI-RADS C4 in breast ultrasonography during the follow-up period. Hazard ratios (HRs) and 95\% confidence intervals (CIs) were determined.

\section{RESULTS}

A total of 647 women who underwent VACB were identified from the patient report of Kosin University Hospital. In this cohort, the median age at diagnosis was 56 years (range, 20-95 years), and 36\% of patients were aged 50 and over. Patients' demographics and BBD data are presented in Table 1. A majority of patients (86.7\%) had a normal body mass index (BMI). Among them, 562 patients (86.9\%) were categorized as group A (post-VACB without recurrence). Group A was more likely to have proliferative lesions without atypia, sclerosing adenosis, and microcalcification. According to the post-VACB pathology report, most BBDs were heterogeneous. Fibrocystic changes were found in 579 tumors (89.5\%), intraductal papillomas in 99 tumors (15.3\%), proliferative lesions in 103 tumors (15.9\%), sclerosing adenosis in 49 tumors (7.6\%), radial scars in 41 tumors (6.3\%), apocrine metaplasia in 34 tumors (5.3\%), and ADH in 37 tumors (5.7\%). Reoperation was done in 37 patients with $\mathrm{ADH}$ due to safety concerns about surgical margins. Furthermore, patients were followed up for 6 months intervals. During the follow-up periods, 85 patients were diagnosed as group B, and biopsies were taken. According to the second pathology reports, fibrocystic diseases were found in 77 (90.6\%), intraductal papillomas in 19 (22.4\%), proliferative diseases without atypia in 22 (25.9\%), sclerosing adenosis in 13 (15.3\%), radial scars in two (2.3\%), and apocrine metaplasia in six (7.0\%) tumors (Table 2). For analysis 
Table 1. Patient and tumor characteristics $(n=647)$

\begin{tabular}{|c|c|c|c|c|}
\hline Characteristic & $\begin{array}{c}\text { Group A } \\
(n=562) \\
\text { No. }(\%)\end{array}$ & $\begin{array}{l}\text { Group B } \\
(n=85) \\
\text { No. }(\%)\end{array}$ & $\begin{array}{c}\text { Total } \\
(n=647) \\
\text { No. }(\%)\end{array}$ & $p$-value \\
\hline Age $(y r)^{*}$ & 45.7 & 43.9 & & 0.191 \\
\hline Age of menarche $(y r)^{*}$ & 15.0 & 14.8 & & 0.757 \\
\hline Status of marriage & & & & 0.902 \\
\hline Married & $414(73.7)$ & $61(71.8)$ & $475(73.4)$ & \\
\hline Not married & $76(13.5)$ & $13(15.3)$ & $89(13.8)$ & \\
\hline Missed & $72(12.8)$ & $11(12.9)$ & $83(12.8)$ & \\
\hline Total & $562(86.9)$ & $85(13.1)$ & $647(100)$ & \\
\hline Age of marriage $(y r)^{*}$ & 25.7 & 25.6 & & 0.976 \\
\hline $\begin{array}{l}\text { Age of menopause } \\
(\mathrm{yr})^{*}\end{array}$ & 48.6 & 46.2 & & 0.005 \\
\hline $\begin{array}{l}\text { Family history of } \\
\text { breast cancer }\end{array}$ & & & & 0.029 \\
\hline Positive & $24(4.3)$ & $2(2.4)$ & $26(4)$ & \\
\hline Negative & $220(39.1)$ & $22(25.9)$ & $242(37.4)$ & \\
\hline Unknown & $318(56.6)$ & $61(71.8)$ & $379(58.6)$ & \\
\hline $\begin{array}{l}\text { Body mass index } \\
\left(\mathrm{kg} / \mathrm{m}^{2}\right)\end{array}$ & & & & 0.789 \\
\hline Normal & $364(64.8)$ & $55(64.7)$ & $419(64.8)$ & \\
\hline High & $36(6.4)$ & 7 (8.2) & $43(6.6)$ & \\
\hline Unknown & $162(26.8)$ & $23(27.1)$ & $185(28.6)$ & \\
\hline Fibrocystic change & & & & 0.449 \\
\hline Positive & $502(89.3)$ & 77 (90.6) & $579(89.5)$ & \\
\hline Negative & $60(10.7)$ & $8(9.4)$ & $68(10.5)$ & \\
\hline $\begin{array}{l}\text { Atypical ductal } \\
\text { hyperplasia }\end{array}$ & & & & 0.356 \\
\hline Positive & $31(5.5)$ & $6(7.1)$ & $37(5.7)$ & \\
\hline Negative & $531(94.5)$ & $79(92.9)$ & $610(94.3)$ & \\
\hline Intraductal papilloma & & & & 0.144 \\
\hline Positive & $80(14.2)$ & $19(22.4)$ & $99(15.3)$ & \\
\hline Negative & $482(85.8)$ & $66(77.6)$ & $548(84.7)$ & \\
\hline $\begin{array}{l}\text { Proliferative diseases } \\
\text { without atypia }\end{array}$ & & & & 0.008 \\
\hline Positive & $81(14.4)$ & $22(25.9)$ & $103(15.9)$ & \\
\hline Negative & $481(85.6)$ & $63(74.1)$ & $544(84.1)$ & \\
\hline Sclerosing adenosis & & & & 0.007 \\
\hline Positive & $36(6.4)$ & $13(15.3)$ & $49(7.6)$ & \\
\hline Negative & $526(93.6)$ & $72(84.7)$ & $598(92.4)$ & \\
\hline Radial scars & & & & 0.074 \\
\hline Positive & $39(6.9)$ & $2(2.4)$ & $41(6.3)$ & \\
\hline Negative & $523(93.1)$ & $83(97.6)$ & $606(93.7)$ & \\
\hline Calcification & & & & $<0.001$ \\
\hline Positive & $20(3.6)$ & 15 (17.6) & $35(5.4)$ & \\
\hline Negative & $542(96.4)$ & $70(82.4)$ & $612(94.6)$ & \\
\hline Apocrine metaplasia & & & & 0.281 \\
\hline Positive & $28(5.0)$ & $6(7.1)$ & $34(5.3)$ & \\
\hline Negative & $534(95.0)$ & $79(92.9)$ & $613(94.7)$ & \\
\hline
\end{tabular}

Group $A=$ those without recurrent mass in breast ultrasonography during follow up periods after vacuum-assisted core biopsy (VACB); group $B=$ those with recurrent mass diagnosed as more than scores of Breast Imaging-Reporting and Data System C4 in breast ultrasonography after VACB.

*Mean.
Table 2. Histopathologic results of core needle biopsy about group B

\begin{tabular}{lc}
\hline & $\begin{array}{c}\text { Total }(\mathrm{n}=85) \\
\text { No. }(\%)\end{array}$ \\
\hline $\begin{array}{l}\text { Fibrocystic change } \\
\text { Positive }\end{array}$ & $77(90.6)$ \\
Negative & $8(9.4)$ \\
Intraductal papilloma & \\
$\quad$ Positive & $19(22.4)$ \\
Negative & $66(77.6)$ \\
Sclerosing adenosis & \\
Positive & $13(15.3)$ \\
Negative & $72(84.7)$ \\
Radial scars & \\
Positive & $2(2.3)$ \\
Negative & $83(97.7)$ \\
Apocrine metaplasia & \\
Positive & $6(7.0)$ \\
Negative & $79(93.0)$
\end{tabular}

Group $B=$ those with recurrent mass diagnosed as more than scores of Breast Imaging-Reporting and Data System C4 in breast ultrasonography after vacuum-assisted core biopsy.

Table 3. Clinicopathological variables for 1 -year recurrence-free survival rate in univariate analysis

\begin{tabular}{lcc}
\hline & HR $(95 \% \mathrm{Cl})$ & $p$-value \\
\hline $\mathrm{BMI}\left(\mathrm{kg} / \mathrm{m}^{2}\right)$ & $0.511(0.219-1.193)$ & 0.286 \\
Fibrocystic change & $0.859(0.414-1.782)$ & 0.683 \\
Atypical ductal hyperplasia & $0.657(0.285-1.511)$ & 0.319 \\
Intraductal papilloma & $0.571(0.342-0.953)$ & 0.032 \\
Proliferative diseases without atypia & $0.558(0.343-0.907)$ & 0.018 \\
Sclerosing adenosis & $0.707(0.391-1.280)$ & 0.253 \\
Radial scars & $2.953(0.726-12.011)$ & 0.130 \\
\hline
\end{tabular}

$\mathrm{HR}=$ hazard ratio; $\mathrm{Cl}=$ confidence interval; $\mathrm{BMI}=$ body mass index.

accounting for various confounding factors, group B was significantly associated with proliferative diseases without atypia, sclerosing adenosis, and microcalcification compared to group A $(p=0.008$, $p=0.007$, and $p=0.001$, respectively). After adjustment for confounding variables, group B was associated more with proliferative breast diseases than group A (HR, 0.558; 95\% CI, 0.343-0.907; $p=0.018)$. Furthermore, group B was associated with intraductal papilloma (HR, 0.571; 95\% CI, 0.342-0.953; $p=0.032$ ). However, group B was not associated with high BMI (HR, 0.511; 95\% CI, 0.219-1.193; $p=0.286$ ) (Table 3).

\section{DISCUSSION}

Breast tumors can recur at the original site (called local recurrence). 
Local recurrence is usually found on breast ultrasound during a follow-up examination by a health care provider or if a morphologic change is observed. Recurrence is usually found when breast ultrasound is reported as BI-RADS C4 during follow-up. When a local recurrence is observed, it is diagnosed in a similar manner as that used for the diagnosis of the first breast tumor. The tumor is biopsied by the surgeon and examined by the pathologist. Tests are done to ensure that there is no sign of malignancy. In our study, there was no evidence of malignancy on pathology reports. Hence, most cases were diagnosed as BI-RADS C4 on breast ultrasonography during follow-up. Post-VACB scar formation was believed to have influenced the diagnosis of BI-RADS C4 on breast ultrasound. Developments in imaging diagnostics and relatively good availability of devices for performing mammography and ultrasound has increased the detection of breast focal lesions at the preclinical stages [6]. The differential diagnosis of small, impalpable focal lesions suspected of a malignant process is especially difficult $[8,9]$. Until recently, the gold standard treatment for such cases was an open surgical biopsy. However, the possibility of developing complications, the length of the procedure, high costs, formation of scars, and frequent occurrence of breast deformation have led to a search for less invasive and less expensive methods [10]. VACB proves to be a method that eliminates or to a large extent limits these disadvantages [11]. It is an efficient, minimally invasive, relatively inexpensive procedure with a good cosmetic effect, and has a low complication rate [12]. Similar to minimally invasive techniques used in the treatment of other organs, VACB, in some cases, can be an alternative to a more extended surgical procedure [13]. This procedure is gradually replacing the commonly used procedure: fine needle aspiration biopsy, whose main disadvantage is a high rate of nondiagnostic results (4\%-35.4\%), as well as false negative findings (2.6\%-20\%). VACB provides multiple quality samples from a single procedure compared to a traditional core biopsy [14]. The diagnostic accuracy of the Mammotome biopsy is $98 \%$ to $100 \%$ for breast lumps [15]. Open surgical biopsy yields similar results, but is more invasive and expensive. In our patients, a sufficient number of samples for histopathological examination were obtained in the first biopsy from 647 patients (99.2\%) [16]. VACB can have therapeutic value, while being well tolerated and associated with low complication rates compared to surgery [17]. In our study, we entirely removed lesions with a low-risk of malignancy using VACB in imaging examinations with an incision diame- ter up to $15 \mathrm{~mm}$ in $94.5 \%$ of women. This is similar to Plantade, who excised entire lesions in $98.1 \%$ of his patients [18]. However, if cases are diagnosed as benign lesions by biopsy, and the lesions are classified as BI-RADS 4a, 4b, 5 by imaging examinations, it is necessary to repeat the biopsy or perform open surgical biopsy as there is a high risk that the cancer may not be completely treated [19]. In conclusion, lesions previously diagnosed as proliferative diseases without atypia or microcalcification during the first VACB were significantly associated with recurrent benign breast tumors. Intraductal papilloma was also significantly associated with tumor regrowth. Therefore, close follow-up is needed for such diagnosis on VACB samples.

\section{CONFLICT OF INTEREST}

The authors declare that they have no competing interests.

\section{REFERENCES}

1. Yamaguchi R, Tanaka M, Tse GM, Yamaguchi M, Terasaki H, Hirai Y, et al. Management of breast papillary lesions diagnosed in ultrasound-guided vacuum-assisted and core needle biopsies. Histopathology 2015;66:565-76

2. Preibsch H, Baur A, Wietek BM, Krämer B, Staebler A, Claussen $\mathrm{CD}$, et al. Vacuum-assisted breast biopsy with 7-gauge, 8-gauge, 9-gauge, 10-gauge, and 11-gauge needles: how many specimens are necessary? Acta Radiol 2015;56:1078-84.

3. Debi U, Thulkar S, Sharma S, Sharma MC, Seenu V, Deo SV, et al. Role of directional vacuum assisted breast biopsy in previously equivocal biopsies for breast masses suspicious for malignancy. Malays J Pathol 2015;37:25-33.

4. Choi ER, Han BK, Ko ES, Ko EY, Choi JS, Cho EY, et al. Initial experience with a wireless ultrasound-guided vacuum-assisted breast biopsy device. PLoS One 2015;10:e0144046.

5. Xu Y, Ming J, Zhou Y, Qi X, Fan L, Jiang J. Mammotome-assisted endoscopic breast-conserving surgery: a novel technique for early-stage breast cancer. World J Surg Oncol 2014;12:99.

6. Pan S, Liu W, Jin K, Liu Y, Zhou Y. Ultrasound-guided vacuumassisted breast biopsy using Mammotome biopsy system for detection of breast cancer: results from two high volume hospitals. Int J Clin Exp Med 2014;7:239-46. 
7. Cheng J, Qiu S, Raju U, Wolman SR, Worsham MJ. Benign breast disease heterogeneity: association with histopathology, age, and ethnicity. Breast Cancer Res Treat 2008;111:289-96.

8. Yi W, Xu F, Zou Q, Tang Z. Completely removing solitary intraductal papillomas using the Mammotome system guided by ultrasonography is feasible and safe. World J Surg 2013;37:2613-7.

9. Jaffer S, Bleiweiss IJ, Nagi C. Incidental intraductal papillomas ( $<2$ $\mathrm{mm}$ ) of the breast diagnosed on needle core biopsy do not need to be excised. Breast J 2013;19:130-3.

10. Wang K, Ye Y, Sun G, Xu Z. The Mammotome biopsy system is an effective treatment strategy for breast abscess. Am J Surg 2013;205: 35-8.

11. Soumian S, Verghese ET, Booth M, Sharma N, Chaudhri S, Bradley $\mathrm{S}$, et al. Concordance between vacuum assisted biopsy and postoperative histology: implications for the proposed Low Risk DCIS Trial (LORIS). Eur J Surg Oncol 2013;39:1337-40.

12. Order BM, Schaefer PJ, Peters G, Eckmann-Scholz C, Hilpert F, Strauss A, et al. Evaluation of two different vacuum-assisted breast biopsy systems: Mammotome(R) system 11G/8G vs. ATEC(R) system 12G/9G. Acta Radiol 2013;54:137-43.

13. Kibil W, Hodorowicz-Zaniewska D, Popiela TJ, Kulig J. Vacuumassisted core biopsy in diagnosis and treatment of intraductal papillomas. Clin Breast Cancer 2013;13:129-32.

14. Jiang Y, Lan H, Ye Q, Jin K, Zhu M, Hu X, et al. Mammotome ( $\left.{ }^{\circ}\right)$ biopsy system for the resection of breast lesions: clinical experience in two high-volume teaching hospitals. Exp Ther Med 2013;6:759-64.

15. Ding B, Chen D, Li X, Zhang H, Zhao Y. Meta analysis of efficacy and safety between Mammotome vacuum-assisted breast biopsy and open excision for benign breast tumor. Gland Surg 2013;2:6979.

16. Wang ZL, Liu G, Huang Y, Wan WB, Li JL. Percutaneous excisional biopsy of clinically benign breast lesions with vacuum-assisted system: comparison of three devices. Eur J Radiol 2012;81:725-30.

17. Abbate F, Cassano E, Menna S, Viale G. Ultrasound-guided vacuum-assisted breast biopsy: use at the European Institute of Oncology in 2010. J Ultrasound 2011;14:177-81.

18. Połom K, Murawa D, Nowaczyk P, Adamczyk B, Giles E, Fertsch S, et al. Vacuum-assisted core-needle biopsy as a diagnostic and therapeutic method in lesions radiologically suspicious of breast fibroadenoma. Rep Pract Oncol Radiother 2010;16:32-5.

19. Wei H, Jiayi F, Qinping Z, Junyi S, Yuan S, Li L, et al. Ultrasound-guided vacuum-assisted breast biopsy system for diagnosis and minimally invasive excision of intraductal papilloma without nipple discharge. World J Surg 2009;33:2579-81. 